\title{
TENTATIVAS PIONERAS DE LEGISLACIÓN \\ LABORAL PARA EL SERVICIO DOMÉSTICO. UNA MIRADA DESDE EL INTERIOR \\ DE LA ARGENTINA: CÓRDOBA EN LA DÉCADA DE 1920
}

\section{Initial attempts at labour law for domestic services. A view from an Argentinian province: Córdoba in the 1920s}

Fernando J. Remedi CONICET / Universidad Nacional de Córdoba, Argentina

\begin{abstract}
Resumen: El trabajo examina las primeras tentativas de intervención del Estado en el servicio doméstico, perfila su carácter, alcance y concepciones subyacentes, así como las razones que impidieron su avance. Dichas iniciativas no se convirtieron en leyes por la ausencia de una presión organizada de los domésticos y, más aún, por las particularidades de esa ocupación laboral. La convivencia y el solapamiento de vínculo laboral y vínculo afectivo entre patrones y trabajadores fue un obstáculo crucial para el avance de la legislación. Se trabajó con documentación del Estado e información de la prensa.
\end{abstract}

Palabras clave: servicio doméstico, desigualdad social, leyes laborales, derechos laborales, regulación.

Abstract: This paper examines the first attempts at state intervention in domestic services and outlines their character, scope, underlying concepts and the reasons that prevented their development. Said initiatives did not turn into law due to a lack of organized pressure from the domestic services and, also, due to the pecularities of this work. The fact that employers and workers lived together and that the work relationship overlapped with the affective relationship was an obstacle for the development of legislation. State documentation and press information were consulted for the writing of this paper.

Keywords: domestic service, social inequality, labour laws, labour rights, regulation. 


\section{Introducción}

Este trabajo se inserta dentro de una línea de indagación dirigida hacia el estudio del mundo de los pobres urbanos en la provincia de Córdoba - centro geográfico de la Argentina - en el giro del siglo XIX al XX, y sus objetivos generales son esclarecer cómo experimentaron estas personas las grandes transformaciones del período, reconstruir su impacto sobre ellos, dando el protagonismo de los de abajo, y analizar cómo actuaron en ese marco de cambios rápidos y profundos. En este sentido, este artículo colabora en la construcción de una historiografía que subraya los costos sociales de los grandes procesos de transformación en forma de desigualdad, pauperización, exclusión y marginalidad, cuestión descuidada por la historia social clásica en sus diferentes versiones dominantes hasta la década de 1980.

En ese marco, en los últimos años la atención se focalizó sobre el servicio doméstico, que puede observarse como un espacio atravesado por sensibles y perdurables asimetrías de clase, es decir, por las distancias sociales que separaron a los patrones de los sirvientes ${ }^{1}$ a lo largo del tiempo, aun cuando estas aparecieran disimuladas bajo el ropaje del paternalismo que, de algún modo, invisibilizaba la relación de explotación existente entre ambas partes. Una hipótesis central en la que se avanzó sostiene que en la Córdoba del cambio del siglo XIX al Xx, en sintonía con el proceso mayor de modernización en curso, se produjo una creciente mercantilización del servicio doméstico, aunque dicho proceso tuvo sus límites. Para fines de la década de 1920, parte de las personas ocupadas en esa actividad aún estaban allí en virtud de colocaciones dispuestas por la Defensoría de Menores, la beneficencia o la familia, como resultado de la prolongada vigencia de prácticas sociales previas a la modernización en curso, que por la fuerza convertían en personal de servicio a una multitud de menores de ambos sexos.

El avance de la mercantilización conllevó una desestabilización de las formas tradicionales de regulación del servicio doméstico - basadas en vínculos paternalistas, arreglos informales y privados entre las partes y lealtades o fidelidades recíprocas - y un debilitamiento relativo del control patronal, aunque sin subvertir la desigualdad que permeaba la relación. En ese contexto, dicho sector de actividad devino ámbito de atención del Estado en sus distintos niveles, con el telón de fondo de los primeros avances estatales sobre el mundo del trabajo, como parte de las respuestas a la cuestión obrera, que atravesaba fuertemente a la denominada cuestión social, emergente en la Argentina hacia el cambio de

1. Para evitar la sobrecarga gráfica que conlleva la utilización de la fórmula «o/a» para aludir a la existencia de dos sexos dentro del colectivo que formaba parte del servicio doméstico, se decidió usar aquí el masculino genérico clásico, aclarando que abarca a varones y mujeres. Cuando se recurre al femenino (sirvientas, domésticas, trabajadoras, etc.) se está aludiendo únicamente a las mujeres que se desempeñaban en el servicio, que en la época representaban la amplia mayoría de ese sector ocupacional en Córdoba. 
centuria. ${ }^{2}$ Siguiendo a Cristina Borderías (2007: 21), la legislación laboral es el mecanismo más directo de intervención estatal en la organización del trabajo y, a través de ella - entre otros medios - el Estado contribuye a la segmentación del mercado de trabajo.

Sobre el particular, en el caso del servicio doméstico en la Argentina, recién promediando la década de 1910 comenzaron a presentarse en el Congreso nacional algunos proyectos legislativos - que no prosperaron - sobre derechos laborales para los trabajadores del sector, cuestión ya examinada por Cecilia Allemandi (2017) y, sobre todo, por Inés Pérez (2015). El objetivo de este trabajo es examinar las primeras tentativas legislativas de intervención reguladora del Estado provincial de Córdoba sobre el servicio doméstico, perfilar su carácter, alcance y concepciones subyacentes, y reconstruir las circunstancias de su tratamiento parlamentario, tratando de esclarecer las razones que obstaculizaron su aprobación. Se trabajó con documentación oficial del Estado provincial - proyectos parlamentarios, mensajes del gobernador, actas de sesiones de la legislatura local $-{ }^{3}$ y con información diversa provista por la prensa local, ${ }^{4}$ de diversas orientaciones políticas e ideológicas, con especial atención en editoriales, notas de actualidad y de opinión. De esta manera, aquí decidimos deslizar la escala de observación desde el Estado central y sus organismos nacionales hacia el provincial, con la intención de examinar su intervención sobre el mundo del trabajo del servicio doméstico, atendiendo, según la fórmula de Ernesto Bohoslavsky y Germán Soprano (2010: 27), a la «multiplicidad de rostros estatales», dejando de mirar al Estado «desde su corazón», las ciudades capitales y las agencias del Ejecutivo nacional. De este modo, se pretende contribuir a la elaboración de un relato histórico más complejo y matizado sobre dicha cuestión. Nos deslizamos también en el tiempo, remontándonos un tanto más atrás del período en el cual, salvo una excepción (Allemandi, 2017), se posa la mirada de quienes en la Argentina se interesaron por el servicio doméstico y sus relaciones con el Estado, que prácticamente inicia en la década de 1920 (Pérez, 2015; Pérez, Cutuli y Garazi, 2018; Portelli, 2020), y rastreamos los antecedentes legales - reducidos solo al ámbito del Congreso en la capital nacional - previos a la sanción de una normativa específica para la actividad que estableció un ré-

2. Juan Suriano (2000: 2), siguiendo la definición de cuestión social de James Morris para el caso chileno, que considera válida para la Argentina, entiende por ella la totalidad de las consecuencias sociales, laborales e ideológicas de la industrialización y urbanización nacientes en el cambio del siglo XIX al XX. Suriano precisa que «cuestión social» es un concepto más abarcador y ajustado que el de «cuestión obrera», porque este último remite específicamente a los problemas derivados de las relaciones laborales.

3. Archivo Histórico de la Legislatura de Córdoba (AHLC). Cámara de Diputados (Diputados). Actas de Sesiones (Actas). Años 1927-1930; Cámara de Senadores (Senadores). Actas de Sesiones (Actas). Años 1928-1930; Archivo. Años 1928-1932.

4. Hemeroteca de la Legislatura de la Provincia de Córdoba (HLPC). El País (EPS). Córdoba, años 1926-1930; La Voz del Interior (LVI). Córdoba, años 1911-1912, 1914, 1916, 1919-1921, 19241926, 1928-1930, 1936. Archivo del Arzobispado de Córdoba (AAC). Los Principios (LP). Córdoba, años 1894-1930, 1936. Círculo Sindical de la Prensa y la Comunicación de Córdoba (CISPREN). Centro de Documentación Juan Carlos Garat (CD). Córdoba (CBA). Córdoba, años 1928-1930, 1936-1937. 
gimen especial para ella, como ocurrió con el Decreto-ley 326 del año 1956 del Gobierno de facto de entonces (Tizziani, 2013). ${ }^{5}$ Así, la construcción de las políticas laborales estatales dirigidas hacia el servicio doméstico se inserta dentro de un proceso histórico mayor y de más larga data, dado que, como subraya Lorena Poblete (2015: 7), una tensión entre regulaciones formales e informales de dicho sector de actividad parece recorrer buena parte de su historia.

Esta historia continúa escribiéndose hoy y sigue atravesada por esa tensión, pese a los significativos avances plasmados en la legislación laboral argentina sobre el sector en las últimas décadas. En el año 2013, el Gobierno nacional sancionó la Ley 26844, que estableció el Régimen Especial de Contrato de Trabajo para el Personal de Casas Particulares, que sustituyó al Decreto-ley de 1956 antes aludido, y amplió los derechos y reguló las condiciones laborales para quienes trabajan en el servicio doméstico. En virtud de esa ley, una serie de beneficios sociales y laborales alcanzaron a todos los trabajadores del sector, con independencia de la cantidad de horas trabajadas, cuestión no menor si se tiene en cuenta que una característica de la actividad es la existencia de jornadas parciales para uno o varios empleadores simultáneamente.

Ese avance legislativo podría estimarse como una manifestación local de una dinámica de orden más general, dentro del ámbito latinoamericano, en desarrollo por lo menos desde la década del 2000 , consistente en una tendencia reformista en el marco legal laboral relativo a los trabajadores del servicio doméstico (Lexarta, Chaves y Carcedo, 2016: 19). Incluso, en una escala más global, debe destacarse que la Organización Internacional del Trabajo desde el año 2009 impulsó la adopción de una norma internacional para protegerlos y que, en esta dirección, en 2011 la Conferencia Internacional del Trabajo adoptó el Convenio núm. 189 sobre el Trabajo Decente para las Trabajadoras y los Trabajadores Domésticos, con el objeto de promover y asegurar sus derechos laborales. Entre estos, se incluye el de contar con un contrato que fije las condiciones de trabajo, que sea claro y comprensible y - preferiblemente- escrito. Numerosos países del mundo, y latinoamericanos en particular, ya ratificaron el convenio, entre ellos la Argentina, en el año 2014.

Sin embargo, el incremento y el mejoramiento del marco legal no necesariamente supone, de manera inmediata y automática, una promoción social de los trabajadores domésticos directamente proporcional al progreso de derecho laboral. Las reformas legales por sí solas no logran mejorar las condiciones del trabajo doméstico y sacarlo de la informalidad (Lexarta, Chaves y Carcedo, 2016: 43). En este sentido, basta recoger algunos resultados brindados por una publicación muy reciente sobre la situación de las trabajadoras del servicio doméstico en la Argentina en el primer trimestre del año 2020, basados en datos

5. El decreto-ley en cuestión, conocido como Estatuto del Servicio Doméstico y de alcance nacional, reguló esta actividad y reconoció algunos derechos laborales para los trabajadores del sector, como las vacaciones pagadas, la licencia por enfermedad, la indemnización por despido, el preaviso y los aportes al sistema de previsión social. No obstante, las protecciones creadas al amparo de esta normativa eran más restringidas que las ofrecidas a otros muchos sectores del mundo del trabajo por la legislación laboral vigente. 
de la Encuesta Permanente de Hogares de 31 grandes ciudades del país, que comprenden a casi 900.000 personas de dicho sector, el 98,5\% de ellas mujeres (Shokida, 2020). De estas, el 74,5\% carece de descuento jubilatorio - que en su momento le daría acceso a jubilación o retiro-, el 68,8\% no tiene vacaciones pagadas, el $68,1 \%$ no percibe aguinaldo - salario anual complementario-, el 70,9\% no recibe pago en caso de enfermedad y el 73,2\% no tiene cobertura de salud mediante obra social. A ello hay que añadir que el trabajo doméstico dentro del femenino es la rama de actividad con la mayor tasa de informalidad y los ingresos promedio más bajos, de bolsillo y por hora trabajada (Shokida, 2020).

Esos datos del presente son indicadores suficientemente reveladores y elocuentes de la experiencia vivida por las trabajadoras domésticas en hogares ajenos y de la brecha que la distancia del frío texto legal que encuadra la actividad. De aquí, entonces, la necesidad de acompañar la actualización de las normativas con políticas públicas activas para la promoción de la formalización del trabajo doméstico, de la cual es parte fundamental - aunque no única - la universalización de la seguridad social en una dirección tal que contemple la especificidad del trabajo doméstico, sobre todo la parcialidad de la jornada laboral y la multiplicidad de patrones, además de la baja capacidad contributiva del sector (Lexarta, Chaves y Carcedo, 2016: 15, 44).

\section{La reglamentación del servicio doméstico ${ }^{6}$}

En Córdoba, en las décadas de 1900 y 1910, desde el ámbito público se promovieron algunas iniciativas regulatorias que supusieron un intento -tímido y fallido - de intervención del Estado en el mundo del trabajo del servicio doméstico. En general, esas iniciativas, impulsadas desde la administración municipal y/o desde la institución policial, buscaban reglamentar - según la terminología al uso en la época - ese sector de actividad; para ello se pretendía implementar diferentes dispositivos que incidían sobre las personas que se desempeñaban en el sector y que propiciaban una fiscalización más estricta de ellas, en concreto, de su identidad, su honradez, sus cualidades morales y sus condiciones sanitarias. Esos intentos de reglamentación se materializaron, en algún caso, en la confección de un registro policial obligatorio de todas las personas que se ocupaban en el servicio doméstico urbano y, en otros casos, en cambio, lo hicieron en la aspiración de crear una oficina de colocaciones sectorial oficial - municipal o policial, según el caso considerado- a la que acudirían por voluntad propia oferentes y demandantes de esa actividad, y en la que a los primeros se les exigiría una certificación de buena conducta otorgada por las fuerzas de seguridad locales. Más allá de sus variantes, esas tentativas reglamentaristas compartían la intención de salvaguardar la propiedad y la salud de las familias a

6. Aquí se recogen de manera en extremo escueta $-\mathrm{y}$ con añadidos - los resultados expuestos en otro trabajo (Remedi, 2020). 
las cuales el personal de servicio brindaba sus prestaciones, en un contexto de creciente extrañamiento entre ambas partes de la relación laboral, consecuencia de la mayor mercantilización de ese sector de actividad desde el último tercio del siglo XIX (Remedi, 2012; 2014).

Dichas iniciativas de reglamentación no pretendían inmiscuirse en la relación laboral propiamente dicha entre los patrones y el servicio doméstico. Sin embargo, para lo que nos interesa en este trabajo, algunas de esas regulaciones, aunque de modo secundario, a veces conllevaron un intento - aunque tímido e infructuoso - de avanzar en esa dirección, al proponer la instauración de un espacio de arbitraje conciliador entre ambas partes en caso de conflicto laboral. Esto aparece explícitamente en dos iniciativas reglamentaristas del período.

La primera de ellas se materializó en un proyecto de ordenanza, aprobado en la ciudad de Córdoba en el año 1917, ${ }^{7}$ en virtud del cual se creaba la Sección Municipal de Colocaciones del Servicio Doméstico, encargada de elaborar y mantener un registro oficial de oferentes y demandantes de la actividad. En relación con el objeto del presente trabajo, interesa subrayar que, detrás de ese objetivo declarado, en la norma se deslizaban algunos artículos que impulsaban, de hecho, el establecimiento de una novedosa instancia de intervención estatal en el mundo del trabajo del servicio doméstico. En efecto, cuando el personal doméstico se contratara con la intermediación de la aludida oficina municipal, en caso de un conflicto contractual entre las partes, se le otorgaba al trabajador involucrado, exclusivamente, el derecho a solicitar la intervención arbitral de dicha repartición pública con el fin de buscar una conciliación laboral. Según la letra de la normativa, a «requerimiento del doméstico», la oficina municipal en cuestión podría ofrecer al patrón una «intervención de amigable composición en los conflictos» devenidos como fruto del «cumplimiento del contrato de locación» de servicios. ${ }^{8}$ La atribución solo al trabajador de la facultad para solicitar la mediación estatal conciliatoria en caso de conflicto contractual reconocía - de hecho - la desigualdad existente entre las partes contratantes y dejaba entrever la voluntad del legislador de equilibrar un tanto la relación de fuerzas que atravesaba al vínculo laboral.

Casi diez años después de la ordenanza aludida, surgió una nueva iniciativa -al igual que las anteriores, muy tímida y frustrada - de creación de una agencia oficial/policial de colocaciones. En 1926, el subcomisario Rómulo Cires, un veterano en actividad de la fuerza policial, promovió - a título personal, elevándolo a sus superiores - un proyecto que proponía establecer, en las comisarías seccionales de la ciudad, una oficina destinada a atender ofertas y demandas de ocupación en general y que, en particular, llevaría un registro específico para el servicio doméstico. Según la propuesta, la «principal misión» de esas oficinas sería «noticiar gratuitamente, al obrero y al empleado, el lugar donde pueden encontrar trabajo». Pero más allá de ello, se atribuía a la máxima autoridad de cada

7. Archivo Histórico de la Municipalidad de Córdoba (AHMC). Actas del Honorable Concejo Deliberante (Actas). Año 1917, ff. 114r-115r; Compilación de las ordenanzas y demás disposiciones dictadas por el H.C. Deliberativo. Año 1917, págs. 15-17.

8. AHMC. Actas. Año 1917, f. 115r. 
comisaría la facultad de intervenir de manera amigable entre las dos partes reunidas por el vínculo laboral en caso de problemas. En efecto, a los comisarios seccionales se les atribuía la capacidad de «entender en los pequeños asuntos entre patrones y empleados, siendo su intervención de mero "arreglo amistoso" [...] a fin de subsanar errores o equivocaciones»; en caso de resultar infructuosa dicha gestión, el comisario tomaría nota de lo actuado y comunicaría a la parte damnificada qué procedimiento debía seguir. ${ }^{9}$ La documentación consultada no deja constancia de la suerte de esta iniciativa, pero tenemos casi la certeza de que nunca fue aprobada o, si lo fue, nunca se implementó, tal como sucedió con la ordenanza de 1917 antes considerada.

\section{De la reglamentación a los derechos}

Las iniciativas de reglamentación antes repasadas, más allá de sus especificidades, se inscribían dentro del marco legal de fondo vigente desde finales del siglo XIX, consagrado en el Código Civil argentino, que colocaba al servicio doméstico bajo la figura jurídica del contrato de locación de servicios, basado en el libre consentimiento de las partes y que presuponía su igualdad, y cuyo artículo núm. 1624 reservaba su reglamentación al ámbito policial o municipal «de cada pueblo». Sin embargo, pese a estas restricciones legales e institucionales definidas por el derecho, hacia mediados de la década de 1910, en el Congreso nacional comenzaron a presentarse proyectos legislativos sobre el servicio doméstico, que, aunque no prosperaron, contemplaban el otorgamiento de algunos derechos laborales, tales como descanso semanal o la inclusión en la ley vigente de accidentes de trabajo 9688 (Allemandi, 2017: 163; Pérez, 2015).

En Córdoba, a mediados de la década de 1920 se empezó a hablar de alguna legislación para el servicio doméstico, cuyos trabajadores iban quedando al margen de los derechos ya consagrados por ley por el Gobierno provincial y por el nacional en beneficio de muchos otros sujetos del mundo laboral. Entre esas leyes implementadas en Córdoba en las primeras tres décadas del siglo xx, que dejaban fuera el servicio doméstico, se encontraban la núm. 1950, de descanso dominical (1907), que excluía explícitamente a dicho sector - por decreto reglamentario de 1928 sí comprendía al personal de servicio de fondas y hoteles -; la núm. 2784, de jornada laboral de ocho horas y cierre de comercios a las 20 horas (1919); la núm. 2712, de sillas (1918); y la núm. 3366, de prohibición del trabajo nocturno en panaderías (1925). A ellas se añadían otras nacionales, tales como la núm. 9688, de accidentes del trabajo (1915); las núm. 5291 y núm. 11317, de trabajo de mujeres y menores (1907 y 1924, respectivamente); la núm. 11338, de prohibición del trabajo nocturno (1926); y la núm. 11544, de jornada legal del trabajo - ley de las ocho horas - (1929), que excluía expresamente a los trabajadores del servicio doméstico, agrícolas y ganaderos. Muchas

9. «Será creada una agencia policial de colocaciones?». HLPC. EPS. Córdoba, 6 de junio de 1926, pág. 5. 
de esas leyes relativas al mundo laboral en Córdoba habían sido impulsadas por gobiernos provinciales conservadores, del Partido Demócrata. Rafael Núñez y Ramón J. Cárcano, quienes ejercieron la primera magistratura durante parte de los años veinte, consideraban esas normativas como un adelanto significativo - aunque aún incompleto - en materia de legislación social de la provincia, una obra en construcción que estaba en marcha y que, por su novedad, revestía naturaleza experimental, susceptible de revisiones para un mejor ajuste a la realidad social. En este sentido, en su mensaje a las cámaras legislativas en 1921, el gobernador Núñez subrayaba las iniciativas de índole social por él impulsadas y que ya se habían convertido en ley, a las que estimaba como «leyes de ensayo» que representaban «una mejora apreciable» para los trabajadores, a la vez que encarecía la aprobación de su proyecto de constitución de «tribunales de conciliación y arbitraje», que facilitarían «la solución de los conflictos obreros». ${ }^{10}$

En este contexto, desde el Gobierno provincial solo se aludió a alguna legislación para el servicio doméstico en 1925, cuando el por entonces ministro de Gobierno de Ramón J. Cárcano anunció que se enviaría a la legislatura un proyecto sobre jubilación para el personal de servicio.11 Al año siguiente, este mandatario señaló explícitamente que la provincia carecía de un proyecto legislativo sobre jubilaciones para el servicio doméstico y que presentaría uno en ese sentido, "calcado de la legislación alemana»; según lo entendía, se echaba en falta una ley al respecto dentro de lo que ponderaba públicamente como «la adelantada legislación que sobre asistencia social posee la Provincia». ${ }^{12}$ Sobre ese tópico volvió a hacer anuncios en mayo y julio de 1927. Pese a la recurrente reiteración de esa intención, desde la más alta jerarquía del Ejecutivo provincial y desde la prensa, los avances en la consulta de la documentación disponible no permiten tener la certeza de que esa predisposición gubernamental llegara a plasmarse en una iniciativa legislativa efectiva. Despierta la atención el hecho de que, en su último mensaje a las cámaras legislativas, en mayo de 1928, el gobernador Cárcano nada dijo sobre dichas jubilaciones. Es igualmente llamativo que el periódico local El País, de orientación conservadora, anunciara en julio de 1927 que el Gobierno provincial - de dicho signo políticoenviaría en breve a la Legislatura un proyecto de jubilaciones para diversos gremios, entre ellos el personal de servicio, que comprendía en él a «mozos de hoteles, cocineros y sirvientes de familias». ${ }^{13}$ Esto ocurría meses antes de las elecciones para gobernador de marzo de 1928, lo cual despertaba la suspicacia del periódico La Prensa, de Buenos Aires, que veía en la iniciativa un tufillo proselitista y sostenía que las vísperas electorales no eran «los instantes más

10. «Mensaje del gobernador a la Legislatura». AAC. LP. Córdoba, 4 de mayo de 1921, pág. 2.

11. «Política social del gobierno de Córdoba. Jubilación para las sirvientas». HLPC. LVI. Córdoba, 3 de julio de 1925, pág. 8 .

12. «Mensaje del Gobernador de la Provincia Dr. Ramón J. Cárcano, presentado el 11 de septiembre de 1926 a la Honorable Legislatura». HLPC. EPS. Córdoba, 17 de septiembre de 1926, pág. 10.

13. «Proyecto de Jubilaciones para diversos gremios». HLPC. EPS. Córdoba, 16 de julio de 1927, pág. 3. 
propicios para legislar en materia de asistencia social», más aún en este caso en que el proyecto sobre jubilaciones era ampliamente comprensivo, entremezclaba en su régimen las actividades más dispares y, además, se desconocían los supuestos estudios en los cuales se había basado. ${ }^{14}$

Como consecuencia de dichas elecciones de marzo de 1928, el Gobierno provincial pasó a manos de la hasta entonces opositora Unión Cívica Radical. A fines de ese año, la nueva administración promovió una legislación laboral para el servicio doméstico que contemplaba derechos sobre extensión de la jornada de trabajo, condiciones materiales de vida, descanso semanal y salario mínimo, entre otros. La intención proclamada que sustentaba la iniciativa era - según expresaban quien estaba en ese momento como representante del Ejecutivo provincial, Américo Aguilera, y el ministro de Gobierno, Amadeo Sabattini - sacar a esos «modestos servidores de la sociedad» de la «situación de verdadera inferioridad material y moral» en la que se hallaban. ${ }^{15}$

Por decreto del poder ejecutivo provincial del 15 de noviembre de 1928, el proyecto en cuestión fue incluido entre los asuntos que debía tratar la legislatura de Córdoba en sus sesiones de prórroga, y se le dio ingreso a la Cámara de Senadores en la sesión del 29 de diciembre de ese año, cuando se decidió su remisión a la Comisión de Legislación para su tratamiento. ${ }^{16}$ Dicha Comisión nunca emitió despacho sobre el proyecto del Ejecutivo, de modo que transcurridos dos años del inicio del trámite legislativo fue enviado al archivo. ${ }^{17}$ No se puede dejar de mencionar que la gestión de la administración provincial que se inicia en 1928 y se extiende hasta la intervención federal a Córdoba, como consecuencia del golpe de Estado que provocó la caída del presidente Yrigoyen en septiembre de 1930, fue un período marcado, entre otras cosas, por una prolongada inactividad de la legislatura, una creciente polarización política e intensos y persistentes enfrentamientos entre las fuerzas políticas dominantes y, sobre todo, el faccionalismo en el interior del radicalismo gobernante.

El proyecto legislativo de 1928 comenzaba estableciendo qué se consideraba como servicio doméstico, y lo definía como «el estado de los empleados a sueldo por otra persona a objeto de consagrarlas a su trabajo y cuidado, sin que puedan ser dedicadas a fines de lucro, directo, comercio o industria». ${ }^{18}$ Para los trabajadores alcanzados por la norma, se estipulaban derechos en materia de condiciones laborales, como contar con «alojamiento higiénico, amueblado y alimentación sana y suficiente», descanso semanal, compensación por despido sin causa justificada - equivalente a un mes de sueldo - a partir de los tres meses de continuidad laboral, salario mínimo (mixto) -50 pesos nacionales, casa

14. «Un proyecto de desconcertante amplitud». HLPC. LVI. Córdoba, 21 de julio de 1927, pág. 9. 15. «El gobierno y el servicio doméstico». HLPC. LVI. Córdoba, 10 de enero de 1929, pág. 9.

16. AHLC. Senadores. Actas. Año 1928, f. 8. El texto del proyecto y el mensaje del ejecutivo que lo acompañaba, suscrito por el gobernador Américo Aguilera, puede verse en: AHLC. Senadores. Archivo. Año 1932 (3), ff. 283-292.

17. AHLC. Senadores. Archivo. Año 1932 (1), f. 29.

18. «El gobierno y el servicio doméstico». HLPC. LVI. Córdoba, 10 de enero de 1929, pág. 9. Cursiva del autor. 
y comida -, y límites - por defecto - a la extensión de la jornada laboral, que se asumía como de diez horas, porque se prescribía que debían disponer de ocho horas continuas para dormir y seis para comidas, instrucción y cuidado de su persona; ${ }^{19}$ dentro de esas seis horas, por tanto, el empleado podría asistir a cursos nocturnos para su instrucción. Por otra parte, quedaba prohibido «absolutamente» el empleo de menores de 14 años, aunque «sin perjuicio» de lo que dispusieran las «leyes especiales», y en el caso de los menores de 18 años, cuando no hubieran cumplido con el mínimo de enseñanza obligatoria, el empleador debía proporcionársela, la jornada de trabajo no podría exceder de ocho horas y su salario sería establecido por "convención de las partes», con autorización de la Oficina Provincial del Trabajo. Toda persona empleada en el servicio doméstico debía proveerse de una libreta, entregada gratuitamente por dicha repartición, donde se registrarían sus datos personales, certificado de estudio, clase de ocupación, horario de servicio y constancia de la aptitud física para el trabajo. La Oficina sería la encargada de supervisar la aplicación de la ley y las infracciones serían penadas con multas de entre 50 y 500 pesos, imputables a los empleadores o patrones, "salvo prueba en contrario». La ley entraría en vigor a los tres meses de su promulgación, y debía ser reglamentada por el poder Ejecutivo. ${ }^{20}$

Hasta ahí el contenido del proyecto elaborado por el Ejecutivo. Una primera observación que se desprende de su texto es que, en virtud de la definición legal que se daba del servicio doméstico, se dejaba fuera del alcance de la normativa a todas aquellas personas que desempeñaban tareas de servicio en empresas -establecimientos comerciales, industriales o de servicios, como hoteles, restaurantes y pensiones $-y$, al parecer, también a aquellas que lo hacían sin percibir un salario por sus tareas, tales como los criados y los colocados - formal o informalmente- entre las familias cordobesas por la Defensoría de Menores, por la beneficencia o por sus padres o tutores. Así, la normativa proyectada consagraba legalmente una desigualdad en el seno del heterogéneo colectivo de los domésticos de la época.

Interesa ahondar en las razones o motivaciones subyacentes al proyecto, tratando de despejarlas del mensaje del ejecutivo que lo acompañó en su tránsito a la legislatura. Al respecto, despiertan la atención varias cuestiones.

La primera de ellas es cierta continuidad con las iniciativas reglamentaristas ya revisitadas, porque detrás del proyecto de 1928 no estaban del todo ausentes los tradicionales argumentos que apuntaban a la búsqueda de seguridad - patrimonial y sanitaria - de las familias empleadoras y, por extensión, de la sociedad en su conjunto, mediante la identificación y el control estatal de los trabajadores. En efecto, en las últimas líneas del mensaje del Ejecutivo se subra-

19. En el marco de la huelga de domésticas en la localidad de Bell Ville, en el interior de la provincia, al año siguiente, entre agosto y septiembre de 1929, las demandas se sintetizaban en un salario mínimo de 60 pesos nacionales, habitación amueblada y diez horas diarias de trabajo, de las cuales las trabajadoras dispondrían de dos a mediodía y otras dos por la noche para sus comidas (Remedi, 2014: 441).

20. AHLC. Senadores. Archivo. Año 1932 (3), ff. 283-292. 
yaba que la pretensión de la iniciativa era «entregar a la sociedad trabajadores físicamente aptos y moralmente sanos, para que en su convivencia con la familia no perturben y constituyan un peligro real para ella y la sociedad toda entera». ${ }^{21}$ Aunque esa pretensión no parece plenamente articulada con lo dispuesto en el texto del proyecto - solo se aludía a una libreta otorgada por la Oficina Provincial del Trabajo, en la que se dejaría constancia de la aptitud física para la labor - , se percibe cierta continuidad argumental con los fundamentos invocados por las demandas sociales de reglamentación del servicio doméstico a la vieja usanza y con las iniciativas oficiales elaboradas en esa dirección, antes reseñadas.

En segundo lugar, la iniciativa pretendía superar el atraso existente en materia de leyes e instituciones y sacar a los domésticos de la situación de marginación legal y laboral en la que se hallaban, equiparándolos un tanto a los demás trabajadores en derechos laborales. Por un lado, se definía al servicio doméstico como un «importante problema social» $y$, a continuación, se enfatizaba en la «situación de verdadera inferioridad material y moral» en la que se hallaban esos «modestos servidores de la sociedad, al margen de leyes y derechos que acuerda la Constitución en su art. 15, donde dice: "En la Nación Argentina no hay esclavos" y en su art. 16 "todos los habitantes son iguales ante la ley" ». La acción del Estado era vista como instrumento de promoción social en materia de derechos, al contribuir a superar los prejuicios vigentes de la sociedad que mantenían dentro de ella a los domésticos como «elementos de atraso y de verdadera contaminación moral».22 Por otro lado, la voz oficial inscribía a los domésticos dentro del mundo del trabajo y del colectivo de trabajadores asalariados, extendiéndoles beneficios y «conquistas alcanzados por el esfuerzo del proletariado». En estos términos, se consideraba necesario que algo se avanzara en derechos laborales en favor de esos asalariados, con el objetivo - en última instanciade convertir a «los domésticos de hoy en los trabajadores del hogar del mañana». En ese sentido, se invocaban referencias - grosso modo- sobre la legislación laboral europea occidental y central relacionada con los domésticos, como el Código Civil alemán de 1900, pero también a disposiciones legales de Suiza, Italia, Dinamarca, Inglaterra y Francia, y se tomaban como ejemplo en América, los casos de México, Uruguay y Brasil, sosteniendo que la Argentina, como país de democracia y libertad, no tenía por qué quedar retrasada respecto de todos esos países.

En tercer lugar, se pensaba que la promoción estatal de mejoras en las condiciones de trabajo por el otorgamiento de algunos derechos actuaría como estímulo para el sostenimiento de la oferta de domésticas en el mercado local, al desalentar el desplazamiento de esas trabajadoras hacia otras actividades asa-

21. Ibídem, f. 288. Cursiva del autor.

22. Los proyectos discutidos a partir de la década de 1920 en el Congreso nacional que buscaron regular el servicio doméstico subrayaban el «atraso» en el que vivían quienes se desempeñaban en la actividad. La necesidad de regulación se fundamentaba en la incompatibilidad entre la condición servil en que vivían la mayoría de los trabajadores del sector y las características democráticas de la sociedad argentina (Pérez, 2015: 48). 
lariadas que ya contaban con alguna cobertura legal laboral. Se trataba, en general, de un deslizamiento desde una ocupación tradicional -el servicio doméstico- hacia otras propiciadas por la modernización en curso, como la industria y el comercio. Hacia mediados de la década de 1920, el secretario de la Oficina del Trabajo de la provincia reconocía explícitamente que la oficina de colocaciones de dicha repartición no lograba cubrir las solicitudes de domésticas de los particulares por su escasísima oferta. Para el funcionario, el atractivo creciente de las condiciones laborales existentes en las alternativas ocupacionales emergentes era la clave explicativa de esa dificultad que enfrentaba la repartición y que perturbaba el equilibrio entre la oferta y la demanda de servicio doméstico. En este sentido expresaba:

\begin{abstract}
El servicio doméstico es realmente escaso y las familias se ven privadas de él, porque todas aquellas personas que se dedican a ese trabajo como único medio de vida, hoy se emplean en los talleres, fábricas, industrias de todo género, en donde solo trabajan ocho horas y con salarios muy superiores. ${ }^{23}$
\end{abstract}

El periódico La Voz del Interior, de orientación radical y progresista, que defendía con vigor el proyecto del Ejecutivo de $1928,{ }^{24}$ subrayaba las deficientes condiciones de trabajo - bajos salarios, jornada laboral muy extendida y sin límite establecido, maltrato patronal, falta de jubilación o asistencia por enfermedad, etc. - como un factor que conducía a las mujeres a preferir otras ocupaciones para ganarse la vida y contribuía a explicar el déficit de oferta de servicio doméstico en relación con su demanda en la ciudad. ${ }^{25}$

Unos años antes, el gobernador demócrata Ramón Cárcano coincidía con ese diagnóstico sociológico cuando enunciaba su ya referida intención de promover una jubilación del personal de servicio. Según el mandatario, se observaba una disminución en el servicio doméstico, que iba «marcándose anualmente como una evolución persistente", y atribuía esta tendencia a las malas condiciones de trabajo vigentes en esa actividad, que alentaban el desplazamiento de las trabajadoras hacia las actividades económicas más modernas, donde gozaban de mejoras laborales. En su mensaje a la Legislatura, Cárcano expresaba en 1926:

La exigua remuneración que percibe, las condiciones particulares de la ocupación, sin horario ni trabajo seguro [, las] induce[n] a buscar ocupación en las fábricas, talleres y casas de comercio en general, donde son mejor remuneradas, más cómodas las condiciones de trabajo [,] permitiendo a veces el aprendizaje de algún oficio y [,] más que todo, que se goza de mayor libertad por la jornada de 8 horas. ${ }^{26}$

23. «LA OFICINA DEL TRABAJO. Una carta de su secretario». AAC. LP. Córdoba, 20 de junio de 1925, pág. 3.

24. Véase el editorial «La ley relativa al Servicio Doméstico. Una iniciativa que resuelve un aspecto del problema social». HLPC. LVI. Córdoba, 3 de enero de 1929, pág. 9.

25. «Oferta y demanda de servicio doméstico». HLPC. LVI. Córdoba, 16 de septiembre de 1930, pág. 8 .

26. «Mensaje del Gobernador de la Provincia Dr. Ramón J. Cárcano, presentado el 11 de septiembre de 1926 a la Honorable Legislatura». HLPC. EPS. Córdoba, 17 de septiembre de 1926, págs. 9-12. 
Meses antes, en el mismo sentido, en una memoria oficial del gobierno de Cárcano se concebía a la jubilación del personal de servicio como «el estímulo» para que las futuras beneficiarias persistieran en esa actividad; allí se expresaba que «la esperanza de un porvenir desahogado» contribuiría a que el servicio doméstico, «virtualmente desaparecido, recobre la efectividad que un tiempo solió tener».27

Volviendo a 1928, de acuerdo con el Ejecutivo provincial radical, en virtud de las condiciones en que desarrollaban su trabajo (y su vida), los domésticos debían gozar de una protección legal por parte del Estado en cuanto que trabajadores. Se trataba de consagrar derechos garantizados por la fuerza de la ley sostenida desde el Estado, y no de concesiones libradas a la buena predisposición o voluntad de los eventuales patrones de turno: «Se afirma que el servicio doméstico, con la convivencia, y la estrecha relación entre el empleador y empleados, conduce a la benevolencia y al despertar de sentimientos que no pueden ser tutelados por las leyes sociales»». ${ }^{28}$ Este es un punto crucial, porque a través de la ley el Estado pretendía inmiscuirse dentro de la esfera privada y del mundo familiar, incidiendo sobre los acostumbrados arreglos informales entre patrones y trabajadores que, históricamente y aún en ese momento, representaban la modalidad dominante de regulación del servicio doméstico y reproducían distintos modos y grados de servilismo. De ahí que en el mensaje de 1928 se sostuviera que en el problema social que representaba el servicio doméstico tenían «intereses creados la casi totalidad de las familias» que componían la sociedad. Para el poder ejecutivo había una evidente desigualdad entre las partes en esa relación laboral que se desenvolvía dentro del hogar del empleador, la cual aparecía algo difusa o menos visibilizada por la (supuesta) incorporación o pertenencia del doméstico a la familia a la cual brindaba sus servicios, debido al desarrollo de vínculos afectivos entre ambas partes. Esa desigualdad era la base de la sobreexplotación del trabajo del doméstico y también, llegado el momento, de su desvinculación de la familia cuando ya no resultaba productivo. Así, el poder ejecutivo expresaba:

\begin{abstract}
Meyer considera la relación del servicio doméstico, no puramente como un contrato sino como vínculo de pertenencia a la consociación familiar; pero este vínculo, de existir, ata al empleado y favorece exclusivamente al empleador, obteniendo un rendimiento de trabajo muchas veces de diez y seis horas al día, privándolo de su descanso hebdomadario, sin siquiera otorgarles los beneficios de la «ley de accidentes» $y$ todas las conquistas alcanzadas por el esfuerzo del proletariado; y cuando la desgracia golpea en las puertas del altillo, para no ver cuadros sombríos, es eliminado de inmediato del seno de la familia y, a lo sumo, se le encarga al portero $u$ a otro doméstico que devuelva al triste y miserable rancho a ese empleado que ha agotado su salud al servicio del patrón, convertido en una piltrafa humana. ${ }^{29}$
\end{abstract}

27. «Jubilación del personal de servicio doméstico». HLPC. LVI. Córdoba, 1 de enero de 1926, pág. 50 .

28. «El gobierno y el servicio doméstico». HLPC. LVI. Córdoba, 10 de enero de 1929, pág. 9.

29. AHLPC. Archivo. Año 1932 (3), ff. 286-287. Cursiva del autor. También puede verse en: HLPC. LVI. Córdoba, 10 de enero de 1929, pág. 9. Cabe advertir que en la versión transcrita e impresa del mensaje que está incorporada en el Diario de Sesiones, el vocablo "contrato» aparece sustituido, equivocadamente, por el de "contacto», lo cual altera sustancialmente el sentido de la 
Como sostiene Poblete, durante muchísimo tiempo, trabajo y afecto aparecieron como dos elementos antinómicos que justificaban el tratamiento del trabajo doméstico como un asunto privado, excluido del ámbito de la regulación estatal (Poblete, 2015: 3). En los debates en el Congreso nacional en torno a proyectos de ley que intentaban regular el servicio doméstico, la convivencia fue uno de los elementos señalados como una característica intrínseca del sector y se enfatizó de modo recurrente para marcar las particularidades de ese tipo de trabajo (Pérez, 2015: 50).

Finalmente, se evidencia la aspiración de promover leyes de protección para los trabajadores que no solo disminuyeran la desigualdad frente a los patrones, sino que también contribuyeran a apuntalar el orden vigente, ya que servirían para desactivar o prevenir las manifestaciones más extremas - convulsivas de la conflictividad social, que hallaba su génesis en el mundo del trabajo. En este sentido, se defendía que la falta de leyes sociales «da la razón al extremismo cuando sostiene que el único camino de redención para las clases necesitadas es la violencia, a la que fatalmente se llega si los gobernantes no saben otorgar justos derechos a todos los habitantes de su pueblo».30

En términos más generales, una finalidad mayor, más esencial, que sobrevuela a todo el mensaje de 1928 y parece ser el hilo conductor del proyecto, es la convicción del Ejecutivo sobre la necesidad de dignificar a las personas que se desenvolvían en el servicio, liberándolas del estado de domesticidad al que se hallaban sometidas - soportando prejuicios y estigmas de vieja data, además de experiencias de gran explotación-, y humanizar las tareas que desarrollaban y el trato que recibían, devolviéndolas - según la expresión utilizada por la voz oficial - como «trabajadores del hogar del mañana». El periódico La Voz del Interior, por entonces cercano a las autoridades provinciales de turno, se hacía eco de esa misma interpretación respecto de los lineamientos generales vertidos en el mensaje del Ejecutivo. En un editorial sobre esta publicación se expresaba así:

\footnotetext{
Un concepto cabal y bien definido campea en el mensaje en que el gobierno acompaña al proyecto de ley de la referencia: es la reivindicación de la personalidad humana, extrayéndola de menguado acervo de domesticidad en que se encuentran los seres desvalidos, obligados por la miseria a servir en la sociedad, desempeñando menesteres ínfimos, reglados por el orgullo y la falsa vanidad con el mismo cartabón con que se medían en la Edad Media las funciones de los esclavos y más tarde el trabajo de los libertos. ${ }^{31}$
}

En ese sentido, se sostenía que el proyecto procuraba que los domésticos salieran de su «infamante categoría de siervos» para que se les tratara y considerara como «proletarios».32

afirmación del ejecutivo. Véase: AHLC. Cámara de Senadores de la Provincia de Córdoba. Diario de Sesiones. Año 1928, pág. 1001.

30. AHLPC. Archivo. Año 1932 (3), f. 286.

31. «La ley relativa al Servicio Doméstico». HLPC. LVI. Córdoba, 3 de enero de 1929, pág. 8. Cursiva del autor.

32. Ídem. 
El proyecto sobre el servicio doméstico impulsado por el Ejecutivo en 1928 no consiguió convertirse en ley; de hecho, la Comisión de Legislación de la Cámara de Senadores a la cual fue destinado ni siquiera emitió despacho al respecto. Dada la escasa información existente en las fuentes disponibles, solo podemos realizar algunas apreciaciones, contextualmente fundamentadas, sobre las razones que podrían explicar esa circunstancia.

En primer lugar, existía una restricción institucional de naturaleza jurídica, materializada en el ya aludido artículo núm. 1624 del Código Civil, que encuadraba al servicio doméstico como un contrato de locación de servicios y colocaba su reglamentación en la órbita de las autoridades municipales o policiales. Aún a mediados de la década de 1930, la prensa local de perfil más conservador apelaba a ese argumento jurídico para pronunciarse en contra de una legislación provincial para dicho sector del mundo del trabajo. ${ }^{33}$

Además, en esa ocasión, el periódico Los Principios introducía otro elemento en su argumentación, que nos conduce a una segunda variable para explicar el infructuoso trámite legislativo de la iniciativa. Según esta publicación, el servicio doméstico, «por su índole y su naturaleza», estaba "a enorme distancia» del que respondía a una actividad comercial o industrial; aquellas personas eran «parte integrante del hogar humano", que no era «un lugar de especulaciones materiales».3. En otras palabras, se trataba de una labor que no perseguía fines de lucro - algo que se explicitaba en el proyecto - y no asimilable a una actividad económica propiamente dicha, generadora de ganancias. Este argumento apareció reiteradamente en los debates legislativos en el Congreso nacional en torno a proyectos que promovían derechos laborales para los domésticos, y sirvieron de fundamento a discursos que enfatizaban la naturaleza particular de la actividad y, por tanto, la necesidad de normas especiales que la regularan (Pérez, 2015: 46; Poblete, 2015: 8). En el mismo sentido, según Los Principios, como «parte integrante del hogar humano", para el doméstico sus derechos "se mueven y conservan dentro de la compleja estructuración del hogar en que sirve». ${ }^{35}$ Más sencillamente dicho, los derechos y las condiciones laborales del personal variaban en cada hogar y caso individual, según los arreglos informales que se concertaban entre cada doméstico y su patrón, tal como se acostumbraba. Así, seguía salvaguardándose el ámbito privado, apartado del Estado y la ley laboral; regulándose informalmente por medio de los tradicionales arreglos privados entre las partes, que preservaban su asimetría en términos de capacidad de negociación. Se hace evidente, entonces, la tensión entre la regulación formal y la informal de la actividad y la resistencia a la penetración del Estado en ese ámbito reservado al contrato privado.

La perdurabilidad y la tenacidad de esas modalidades tradicionales y privadas de arreglo entre patrones y trabajadores deben haber sido variables cruciales para explicar el escaso interés perceptible en los legisladores cordobeses

33. «Notas y comentarios». AAC. LP. Córdoba, 29 de julio de 1936, pág. 2.

34. Ídem.

35. Ídem. 
por el proyecto que buscaba regular el servicio doméstico y consagrar algunos derechos laborales para el sector. Además, otro motivo era que, en el interior del hogar del patrón - como ya se señaló y lo destacaba el mensaje de 1928-, un espacio devenido también lugar de trabajo, el vínculo laboral y el vínculo afectivo se solapaban, creando un obstáculo para la pretendida irrupción del Estado en ese ámbito privado.

Un último aspecto que conjeturamos que pudo haber incidido en la suerte del proyecto remite a la ausencia de una organización gremial de los domésticos y su dispersión a lo largo de una multitud de lugares de trabajo autónomos y, además, inscriptos dentro del ámbito privado de las familias. El periódico Córdoba no dejaba escapar este detalle y aludía explícitamente a la diferencia de género que mantenía el servicio doméstico - conformado por una abrumadora mayoría de mujeres y crecientemente feminizado - ${ }^{36}$ frente a los trabajadores varones agremiados; mientras estos últimos eran capaces de luchar por la conquista de mejoras laborales, aquellas padecían, soportaban, sufrían en silencio y, resignadas, ahogaban su dolor. En sus columnas se afirmaba:

Las organizaciones obreras masculinas recurren a todos los medios vigorosos para abatir la prepotencia patronal y obtener mejoras para su vida miserable. Ellas en cambio sofocan el tumulto de sus rebeldías en el catre roñoso de su pocilga ratonera. Abandonadas de la justicia y de las leyes. ${ }^{37}$

Por lo tanto, las trabajadoras del sector tenían una débil o nula capacidad para incidir sobre la opinión pública y, especialmente, sobre los sectores políticos como para propiciar un clima de ideas u opiniones favorable a una intervención estatal sobre el servicio doméstico que conllevara la consagración de derechos laborales. Continuaba Córdoba:

36. Según datos del Censo Municipal de Córdoba de 1906, una mirada al interior de la categoría personal de servicio revela un nítido sesgo de género: el 95\% eran mujeres. Los datos provistos por el Censo Nacional de Población de 1914 no discriminan entre la ciudad de Córdoba y la provincia homónima, pero apuntan en el mismo sentido, ya que, del rubro «personal de servicio», el 89\% eran mujeres. Véase: Censo General de la Población, Edificación, Comercio, Industria, Ganadería y Agricultura de la Ciudad de Córdoba, levantado en los días 31 de agosto y 1 de septiembre de 1906. Córdoba: La Italia, 1910; Tercer Censo Nacional. Levantado el 1 de junio de 1914. Buenos Aires: Talleres Gráficos de L. J. Rosso y Cía., 1916, t. IV, págs. 254-264. Esa amplia mayoría de mujeres es un indicador del proceso de feminización de dicha actividad. En la ciudad de Buenos Aires, la participación de las mujeres en el servicio pasó del 70 al 90\% en el período 1869-1914 y trepó hasta el 94\% en 1947 (Allemandi, 2017: 75). La feminización de la actividad remite también a las concepciones dominantes en la época, en concreto al creciente acercamiento de aquella al trabajo doméstico no remunerado, más precisamente a la figura del ama de casa (Pérez, Cutuli y Garazi, 2018: 78, 233).

37. «La Primera Rebelión del Servicio Doméstico». CISPREN. CD. CBA. Córdoba, 29 de agosto de 1929, pág. 3. Como muestra de la feminización de la ocupación, cabe señalar que el periódico, a lo largo de todo el artículo, siempre utiliza solo el femenino en alusión a quienes trabajaban en el servicio doméstico. 
Un gremio para quien no hay legislación posible, porque los representantes del pueblo les pareció "demasiado sucio» penetrar en las cocinas y despensas familiares. Un gremio cuya existencia ignorada transcurre entre la escoba y el estropajo, el fogón y la bombilla. ${ }^{38}$

Por eso mismo, el conflicto - visible y espectacular - protagonizado por las domésticas en 1929 en la localidad de Bell Ville, en el interior de la provincia de Córdoba (Remedi, 2014: 440-445), era una llamada de atención para los políticos contemporáneos; ese hecho era el «insulto más grande» que habían recibido «los fabricantes de leyes» de parte de esas "pobres mujeres» a las que ellos "colocaron al margen de toda protección», según el discurso inflamado y parcial del diario Córdoba. ${ }^{39}$

\section{A modo de cierre}

Este trabajo intentó aproximarse al estudio de algunas modalidades formales de regulación del servicio doméstico impulsadas en Córdoba en las primeras décadas del siglo xx. Esto ocurrió en un contexto en el cual estaba en marcha - desde fines del siglo anterior - un proceso de creciente mercantilización de esa actividad, que desestabilizó las formas tradicionales - paternalistas, informales, privadas - de su regulación, como consecuencia de la mayor circulación y movilidad de los trabajadores y el extrañamiento entre ellos y sus patrones.

En este marco, las iniciativas municipales y policiales de reglamentación formuladas en las décadas de 1910 y 1920 apuntaron hacia el despliegue de un dispositivo de control más riguroso de los trabajadores, mediante su individualización y supervisión estatal-policial. Sin embargo, algunas de esas iniciativas también comenzaron a contemplar - aunque tímidamente- ciertas instancias de intervención estatal en la relación contractual del servicio doméstico, que implicaban un arbitraje conciliador en caso de conflicto y parecían inspiradas en la búsqueda de una protección a la más débil de ambas àrtes y de un mayor equilibrio entre ellas, reconociendo implícitamente la desigualdad de clase y poder que atravesaba a ese vínculo.

Esas iniciativas de penetración estatal en el servicio doméstico tuvieron como trasfondo un proceso - lento, gradual y sinuoso - de creciente intervención del Estado - nacional y provincial - en el mundo del trabajo en general, materializado sobre todo en el impulso de leyes laborales que, de a poco, iban consagrando algunos derechos para ciertos sectores de los trabajadores, mientras que se dejaban fuera de los mismos a otros. Entre estos estaba el servicio doméstico, que el marco legal general colocaba bajo la figura del contrato de locación y atribuía su reglamentación al ámbito municipal o policial. Así, el Estado marginalizaba al servicio doméstico y contribuía a reproducir desigualdades dentro del mundo del trabajo y de los trabajadores.

38. Ídem.

39. Ídem. 
Sin embargo, desde mediados de los años veinte, no solo en el ámbito nacional -como ya lo establecieron otros trabajos - , sino también en el provincial - como creemos haber mostrado para Córdoba-, empezaron a formularse iniciativas legislativas que contemplaban el otorgamiento de algunos derechos laborales para los domésticos. Aunque dichas iniciativas preservaban desigualdades en el interior del mundo del trabajo, contribuirían a atemperarlas al extender algunos beneficios de las leyes laborales hasta alcanzar a un sector marginalizado de ellas. Como se expresaba desde el Ejecutivo provincial en 1928 , merced al amparo de la ley, era necesario que algo se avanzara en bien de esos trabajadores.

Pese a las buenas intenciones declaradas por el Ejecutivo en la década de 1920 , ellas no lograron plasmarse en proyectos legislativos o bien, cuando lo hicieron, no solo no se transformaron en leyes, sino que ni siquiera concitaron especial atención de los legisladores encargados de su tratamiento. Así, la marginalización del servicio doméstico respecto de los derechos laborales persistió. Por otra parte, el proyecto remitido a la legislatura en 1928, si bien inscribía a los domésticos dentro del colectivo de proletarios, colaboraba en preservar ciertas desigualdades existentes dentro de los derechos laborales -como la extensión de la jornada, los mecanismos para la fijación del salario, la existencia de un salario mixto, etc. - a la vez que también creaba otras en el interior de los trabajadores del sector, al incidir únicamente sobre aquellos que la ley definía como tales: asalariados en actividades sin fines de lucro. Además, en materia de su fundamentación, el proyecto evidenciaba alguna continuidad con las tentativas previas de reglamentación del servicio doméstico, provenientes sobre todo del brazo policial del Estado, coincidiendo con ellas en la década de 1920, al sostener que se buscaba entregar a la sociedad trabajadores sanos - física y moralmente-, de modo que no fueran un peligro para la familia empleadora y la sociedad en su conjunto.

El proyecto en cuestión no prosperó. Además de la ausencia de una presión organizada desde abajo por parte de los trabajadores, creemos que tuvo una gravitación decisiva la peculiaridad del servicio doméstico como actividad laboral, definida por la convivencia entre patrones y domésticos, la naturaleza no lucrativa de su labor y el tipo de actividades realizadas, estimadas como propias del ama de casa. ${ }^{40}$ La aludida convivencia y el consecuente solapamiento - difuso, ambiguo, permanente, cotidiano - del vínculo laboral y el vínculo afectivo entre patrones y trabajadores, es decir, la coexistencia de trabajo y afecto, constituyeron el obstáculo crucial para el avance de una legislación para el sector, que

40. De modo semejante, para el caso brasileño, un artículo reciente subraya que la concepción del trabajo - si las actividades que hacen a la reproducción cotidiana son una forma de trabajo, si ellas generan valor - fue una de las razones por las cuales el servicio doméstico durante largo tiempo permaneció al margen de la protección legal asegurada a otros sectores del mundo laboral en ese país. Durante el Estado Novo varguista, las personas que se desempeñaban en el servicio doméstico en Brasil fueron excluidas de la Consolidación de las Leyes del Trabajo de los años treinta, porque quienes la elaboraron argumentaron que dicha ocupación no contribuía al lucro del capital y, por lo tanto, debía ser considerada por una regulación específica (Marques, 2020: 185-186, 214). 
supondría una penetración del Estado dentro de la esfera privada y familiar. Ahí se hace evidente la tenacidad de las preexistentes modalidades informales de regulación del servicio doméstico, las cuales, aunque desestabilizadas o conmovidas por su proceso de mercantilización en curso, aún persistían activas.

\section{Bibliografía}

AllemAnd, Cecilia (2017). Sirvientes, criados y nodrizas. Una historia del servicio doméstico en la ciudad de Buenos Aires (fines del siglo XIX y principios del XX). Buenos Aires: Teseo.

BOHOSLAVSKY, Ernesto y SOPRANO, Germán (2010). «Una evaluación y propuestas para el estudio del Estado en Argentina». En: BoHOSLAVSKY, Ernesto y SOPRANO, Germán (eds.). Un Estado con rostro humano. Funcionarios e instituciones estatales en Argentina (desde 1880 a la actualidad). Buenos Aires: Prometeo, págs. 9-55.

BORDERÍAS, Cristina (2007). «Introducción: Instituciones y género en la formación de los mercados de trabajo». En: BorderíAs, Cristina (ed.). Género y políticas del trabajo en la España contemporánea, 1836-1936. Barcelona: Icaria, págs. 9-37.

LeXARTA, Larraitz; Chaves María José y CARCedo, Ana (2016). Políticas de formalización del trabajo doméstico remunerado en América Latina y el Caribe. Lima: Oficina Regional para América Latina y el Caribe de la Organización Internacional del Trabajo. Disponible en: www.oit.org/wcmsp5/groups/public/---americas/---ro-lima/documents/ publication/wcms_480352.pdf (consulta: 5 de diciembre de 2020).

MARQUES, Teresa Cristina de Novaes (2020). «Anatomia de uma injustiça secular. O Estado Novo e a regulaçao do serviço doméstico no Brasil». Varia Historia, Belo Horizonte, 70, págs. 183-216. Disponible en: www.scielo.br/scielo.php?script=sci_arttex t\&pid=S0104-87752020000100183 (consulta: 24 de marzo de 2020).

PÉREZ, Inés (2015). «Un régimen especial para el servicio doméstico. Tensiones entre lo laboral y lo familiar en la regulación del servicio doméstico en la Argentina, 19261956». Cuadernos del IDES, Buenos Aires, 30, págs. 44-67.

PÉreZ, Inés; Cutul, Romina y GaRAzI, Débora (2018). Senderos que se bifurcan. Servicio doméstico y derechos laborales en la Argentina del siglo xx. Mar del Plata: Editorial de la Universidad Nacional de Mar del Plata.

PoBlete, Lorena (2015). «Modos de regulación del trabajo doméstico». Cuadernos del IDES, Buenos Aires, 30, págs. 3-10.

PORTELLI, María Belén (2020). «En busca de derechos. Los trabajadores domésticos en la justicia laboral. Córdoba, 1950-1955». Avances del Cesor, Rosario, 17 (23). Disponible en: http://portal.amelica.org/ameli/jatsRepo/27/271572003/index.html.

REMEDI, Fernando J. (2012). «Esta descompostura general de la servidumbre. Las trabajadoras del servicio doméstico en la modernización argentina. Córdoba, 1869-1906». Secuencia. Revista de Historia y Ciencias Sociales, México D. F., 84, págs. 43-69.

REMEDI, Fernando J. (2014). "Las trabajadoras del servicio doméstico: entre la subordinación y la negociación en una modernización periférica. Córdoba (Argentina), 19101930». Anuario de Historia Regional y de las Fronteras, Bucaramanga, 19 (2), págs. 423-450. Disponible en: https://revistas.uis.edu.co/index.php/anuariohistoria/article/ view/4288/4584. 
REMEDI, Fernando J. (2020). «Los de arriba y los de abajo. El servicio doméstico y su 'reglamentación' en Córdoba (Argentina) en las primeras décadas del siglo XX». HISTOReLo. Revista de Historia Regional y Local, Medellín, 23, págs. 123-156. Disponible en: https://revistas.unal.edu.co/index.php/historelo/article/view/73154/pdf

SHOKIDA, Natsumi S. (2020). "Las trabajadoras de servicio doméstico en Argentina. 1er trimestre de 2020». Economía Femini(s)ta, septiembre. Disponible en: https://ecofeminita.github.io/EcoFemiData/informe_servicio_domestico/trim_2020_01/informe. nb.html (consulta: 5 de diciembre de 2020).

SuriANO, Juan (comp.) (2000). La cuestión social en Argentina, 1870-1943. Buenos Aires: La Colmena.

Tizziani, Ania (2013). «El "Estatuto del Servicio Doméstico" y sus antecedentes: debates en torno a la regulación del trabajo doméstico remunerado en la Argentina». Nuevo Mundo Mundos Nuevos, París, págs. 1-17.

Fecha de recepción: 19 de agosto de 2020

Fecha de aceptación: 9 de diciembre de 2020

Fecha de publicación: 30 de junio de 2021 